\title{
Landsat International Cooperators and Global Archive Consolidation
}

Landsat missions have always been an important component of U.S. foreign policy, as well as science and technology policy. The Landsat program's longstanding network of International Cooperators (ICs), which operates numerous international ground stations (IGSs) around the world, embodies the United States' policy of peaceful use of outer space and the worldwide dissemination of civil space technology for public benefit. Thus, the ICs provide an essential dimension to the Landsat mission.
Historically, IGS reception capabilities have augmented data collection capacity of the Landsat missions above and beyond those provided by the satellite onboard recorders. The historical data downlinked to the IGSs are currently being added to the U.S. Geological Survey (USGS) Landsat archive by way of the Landsat Global Archive Consolidation (LGAC) initiative (https://www.usgs.gov/land-resources/nli/landsat/ landsat-global-archive-consolidation).

\section{Landsat International Cooperator Network}

The current Landsat 7 and Landsat 8 IGSs provide contingency data collection capacity to the Landsat Ground Network (LGN) in the event of a spacecraft anomaly or malfunction, and ICs augment the global data distribution and exploitation of Landsat data (fig. 1). Additionally, the expertise of ICs in applying Landsat data to local and regional user needs can facilitate further USGS scientific and applications development for Landsat data in the United States and worldwide.
The USGS meets with the Landsat ICs twice per year to discuss operational management and technical matters through the Landsat Ground Station Operators Working Group (LGSOWG) and Landsat Technical Working Group (LTWG). The LGSOWG and LTWG meetings are an essential forum for global Landsat cooperation and collaboration. More information about the IC network is provided on the Landsat Missions Web site (https://landsat. usgs.gov/igs-network).

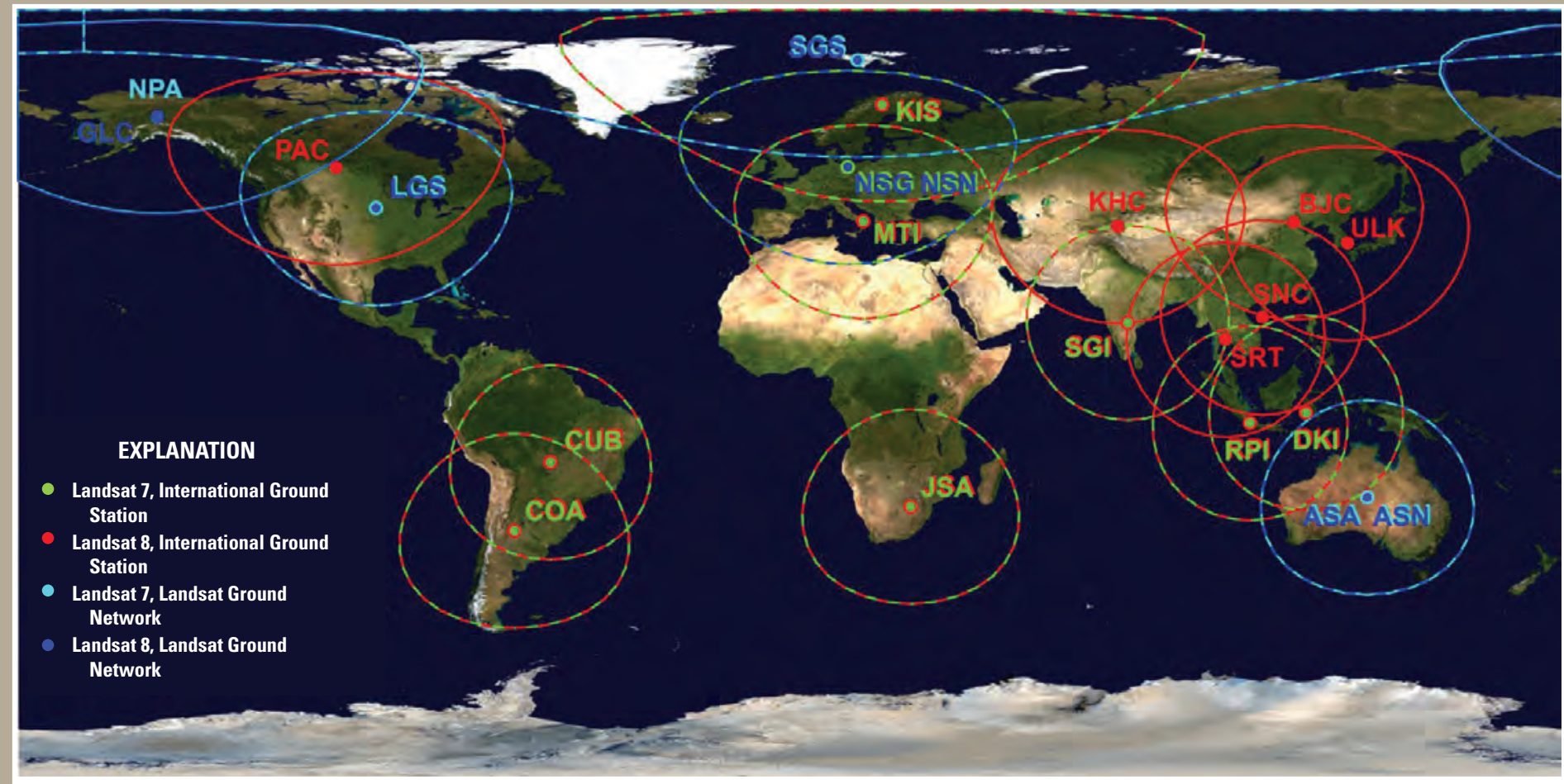

Figure 1. Landsat 7 and Landsat 8 International Ground Stations and Landsat Ground Network. (Current as of June 2019.) 


\section{Landsat Global Archive Consolidation}

Landsat satellites have acquired data from across the globe for more than four decades. Throughout the years, data have been downlinked not only to the USGS Ground Stations, but also to numerous IGSs. Because of recording limitations on early Landsat satellites, significant amounts of data downlinked to and archived at IGSs are unique, relative to each station's area of coverage, and are not duplicated in the USGS archive (https:// landsat.usgs.gov/historical-international-ground-stations).

In 2010, the Landsat Global Archive Consolidation (LGAC) effort began, with goals to consolidate the Landsat data archives of all international ground stations, make the data more accessible to the global Landsat community, and significantly increase the frequency of observations over a given area of interest to improve scientific uses such as change detection and analysis.
Bringing Landsat data from many collection stations worldwide to one archive includes several challenges:

- Various or unknown data formats and processing methods

- Stations that are no longer active

- Media storage age and conditions

- Various or obsolete technologies used to ingest data.

Although some data may not be recoverable, every available technological approach will be explored. The number of scenes added to the USGS archive is shown in figure 2.

As this effort to systematically acquire, reconcile, and ingest all recoverable foreign data continues, all data successfully ingested into the Landsat archive become visible on EarthExplorer (https://earthexplorer.usgs.gov), GloVis (https://glovis. usgs.gov), and the LandsatLook Viewer (https://landsatlook.usgs. gov). More information about LGAC is provided on the Landsat Missions Web site (https://www.usgs.gov/land-resources/nli/ landsat/landsat-global-archive-consolidation).

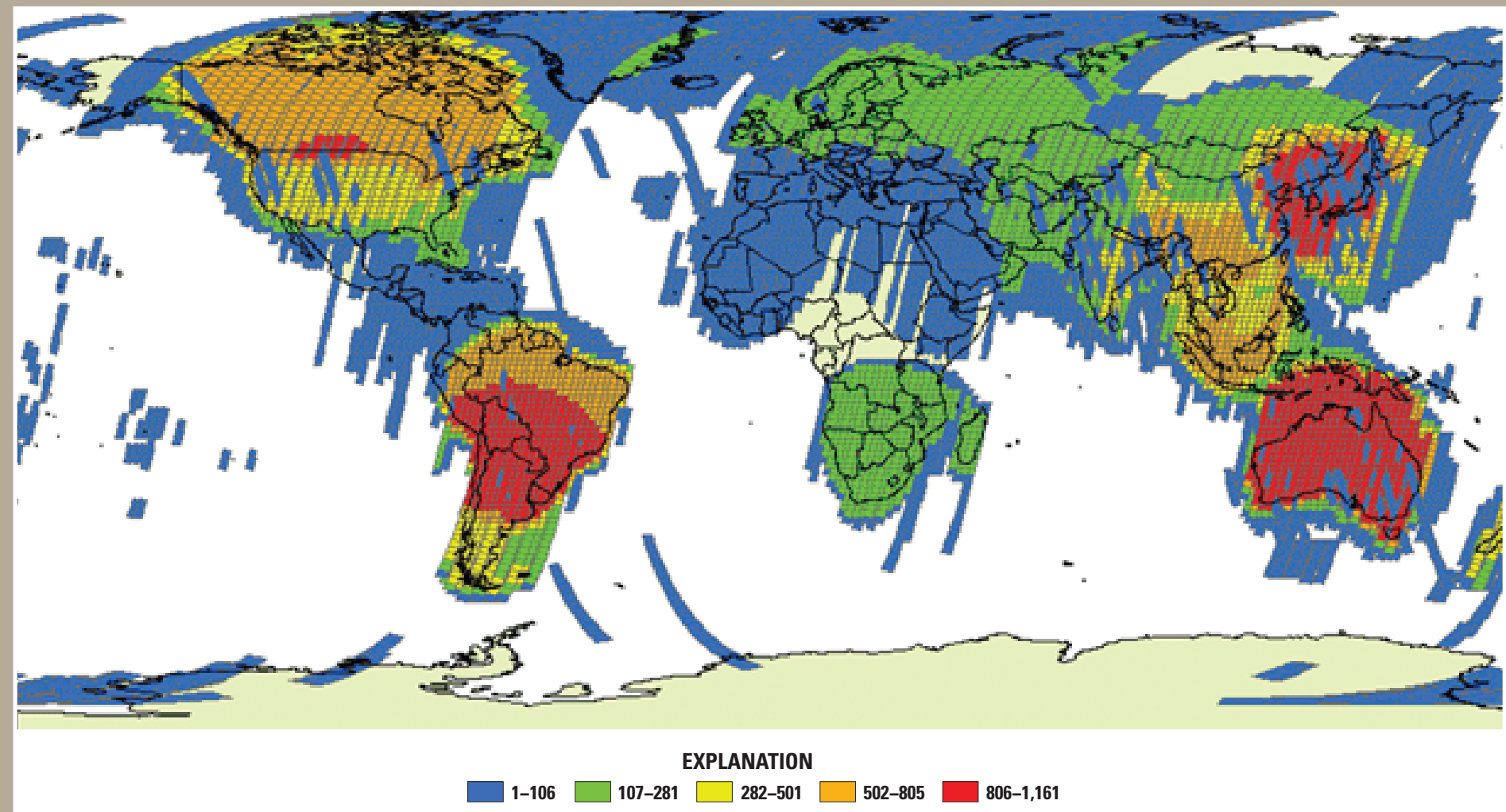

Figure 2. The colors on this map indicate the number of scenes that have been added to the Landsat archive by way of the Landsat Global Archive Consolidation initiative. More than 5 million scenes have been added as of December 2018.

\section{For More Information}

Questions about the Landsat IC Network and LGAC can be directed to:

Landsat User Services

U.S. Geological Survey (USGS)

Earth Resources Observation and Science (EROS) Center

Sioux Falls, SD 57198

Phone: $605-594-6151$ or 1-800-252-4547

Email: custserv@usgs.gov
Twitter: @USGSLandsat

Facebook: https://www.facebook.com/NASA.Landsat

Visit https://www.usgs.gov for more information about the USGS and https://www.usgs.gov/land-resources/national-landimaging-program for specifics about the National Land Imaging Program.

Any use of trade, firm, or product names is for descriptive purposes only and does not imply endorsement by the U.S. Government. 